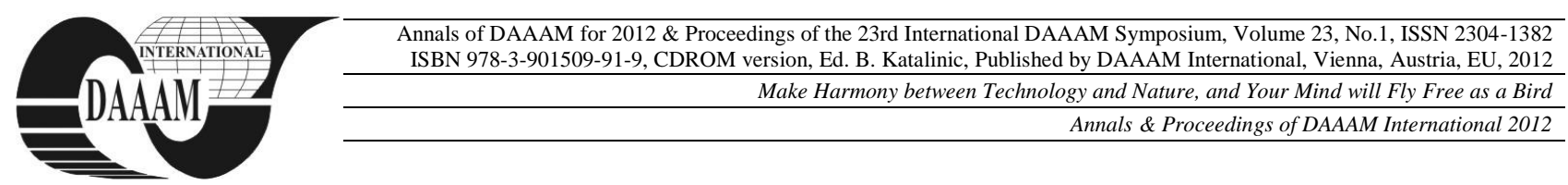

\title{
PLASMA ARC WELDING OF NITI AND 304 STEEL
}

\section{VONDROUS, P[etr]; KOLARIK, L[adislav] \& KOLARIKOVA, M[arie]}

\begin{abstract}
Heterogenous welds of Nitinol and austenitic stainless steel 304 were done by micro plasma welding. Both materials have wide utilization in medicine, especially NiTi is very promisive material, but with rather difficult weldability. The quality of welds was estimated by means of metallography, hardness measurement, and tensile strength test. It was found out that homogenous welding of NiTi as well as heterogenous $N i T i+304$ welds very much decreases mechanical properties. In homogenous weld, strength, hardness drops to $260 \mathrm{HV}$ (BM $350 \mathrm{HV}$ ) because of grain growth. Heterogenous welds have high hardness, up to $800 \mathrm{HV}$ caused by precipitation of brittle intermetalics. PAW was found not to be suitable for nitinol welding.
\end{abstract}

Keywords: Nitinol, NiTi, Stainless steel, 304, Welding, Micro plasma, PAW

\section{INTRODUCTION}

One of the very promisive metallic materials is nitinol (NiTi), which is nearly equiatomic alloy of nickel and titanium. This material, with properties as shape memory and superelasticity, was discovered and described by Buehler in seventies of twentieth centrury [1]. Nitinol is used e.g. for various interventional medical purposes, where its widespread commercial application is stent having shape memory, i.e. stent is inserted cold in contracted shape and activates (expands) inside the body when reaching the body temperature. NiTi superelasticity very well handles continuous distorsion and kinking, typical for implants [2].

Other applications using superelasticity of NiTi in medicine are catheters inserted into arteries, vessles and so on to provide straight-through passage where it was previously blocked. For some catheters it is useful to use NiTi only on part of the product and weld NiTi with other bio intact material, such as stainless austenitic steel. This combination is usefull for price reduction or/and manufacturing improvements.

In background of this project is product development of a venous cathether that is in present state manufactured from stainless steel only. At the present production line, the catheters from 304 steel are microplasma welded. To improve usability of the catheter and to inovate the product, combination of NiTi insert with stainless steel braid was suggested. Such a combination of materials would have better elastic properties. But heterogenous weld NiTi +304 will be needed.

This paper researches weldability of heterogenous joints of NiTi and stainless 304 steel by micro plasma arc welding and usability of existing welding equipment for innovated product design.

\section{MATERIALS AND PRODUCT DESIGN}

Partial drawing of the venous catheter is shown at Fig. 1. The purpose of the product is to be inserted into the body by small hole in the vein and to help surgical operations. The length of such catheter can be between $300-600 \mathrm{~mm}$. The catheter needs to be very elastic and strong at the same moment to be able to go around twists in veins and push through openings.

It is composed from inner wire (diameter $0.38 \mathrm{~mm}$ ) and outer braid (spring like) with outer diameter $0.85 \mathrm{~mm}$ that are manufactured from stainless steel 304. These two parts are welded together at the ends by microplasma welding. NiTi inner wire has on each end tapered ending of reduced area, as visible at Fig. 1. These tapered endings, diameter of only $0.2 \mathrm{~mm}$, are to be welded to outer braid to create smooth semispherical weld.

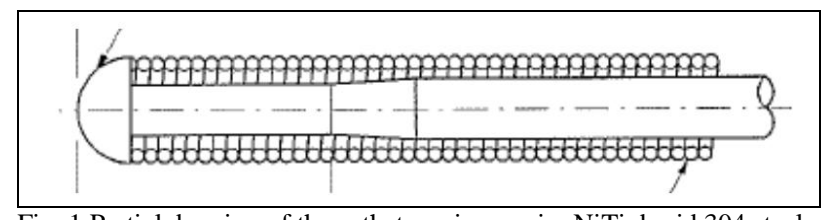

Fig. 1 Partial drawing of the catheter - inner wire NiTi, braid 304 steel

Nitinol presents many good properties as superelasticity, corrosion resistance and biocompatibility. Furthermore the shape, stiffness and other properties of NiTi can be controlled by chemical composition, heat treatment and temperature [1]. Two allotropic modifications of nitinol are martensitic and austenitic. Phases depend on chemical composition, temperature and stresses. NiTi is produced by melting in deep vacuum, without any presence of $\mathrm{O}, \mathrm{W}, \mathrm{C}, \mathrm{Fe}, \mathrm{N}, \mathrm{H}$. When wire drawn, continuous annealing is done around $450-550^{\circ} \mathrm{C}$ followed by quench in water.

It is generally known that drawbacks of nitinol are bad machinability, because of its elasticity and hard $\mathrm{TiO}_{2}$ surface, and problematic weldabilty. Nitinol weldability is problematic because of several reasons: 1 . Ti and $\mathrm{Ni}$ have many different termo-physical properties (e.g. melting points, heat conductivities) that make necessary well controlled production process in vacuum. 2. NiTi properties, phase transformation temperatures depend on chemical composition. Small change of chemical composition due to diffusion (welding) causes change of properties of alloy. 3. Titanium is highly reactive with gasses as $\mathrm{N}_{2}, \mathrm{O}_{2}$. Brittle oxides $\mathrm{TiO}_{2}$, $\mathrm{TiN}_{2}$ can form. 4 . By welding or uncontrolled heating brittle intermetallics $\mathrm{NiTi}_{2}, \mathrm{Ni}_{4} \mathrm{Ti}_{3}, \mathrm{Ni}_{4} \mathrm{Ti}_{2}$ can be created. 5 . Welding with ferrous metals forms brittle intermetalics [3]. 
The researchers are not in unison, whether the mechanical properties are preserved (tensile strength, superelasticity) when homogenous NiTi welds are done. In some researches serious decrease of mechanical properties by $40-60 \%$ is noted [4, 5], while in other sources state that decrease of properties is minimal $[6,7]$.

The literature sources agree on big influence of processing parameters on quality of the welds. Especially high heat input in the weld was found to have detrimental influence on weld quality $[6,7,8]$.

Chemical composition of nitinol and 304 steel is shown in Tab. 1. This nitinol composition is the most typical NiTi alloy used in medical industry [2]. It is of austenitic phase with high plateau of superelastic behavior.

\begin{tabular}{|c|c|c|c|c|c|c|c|}
\hline $\begin{array}{c}\text { Stainless steel } \\
304\end{array}$ & $\mathrm{C}$ & $\mathrm{Co}$ & $\mathrm{Cr}$ & $\mathrm{Cu}$ & $\mathrm{Mn}$ & $\mathrm{Ni}$ & $\mathrm{Fe}$ \\
\hline [Wt. \%] & 0,008 & 0,06 & 18,5 & 0,1 & 1,28 & 10 & Rest \\
\hline NITINOL & $\mathrm{Ni}$ & $\mathrm{Ti}$ & & & & & \\
\hline [Wt. \% / at.\%] & $56 / 51$ & $44 / 49$ & & & & & \\
\hline
\end{tabular}

Tab. 1. Chemical compostition of steel 304 and nitinol

Basic physical and mechanical properties of both metals are stated in Tab. 2.

\begin{tabular}{|l|c|c|}
\hline & NiTi & 304 \\
\hline Density $[\mathrm{g} / \mathrm{cm} 3]$ & 6,5 & 8 \\
\hline Fusion temp $\left[{ }^{\circ} \mathrm{C}\right]$ & $1240-1310$ & 1450 \\
\hline $\begin{array}{l}\text { Thermal conductivity } \\
{\left[\mathrm{W} / \mathrm{m}^{\circ} \mathrm{C}\right]}\end{array}$ & 18 & 16 \\
\hline Heat capacity $\left[\mathrm{J} / \mathrm{g}^{\circ} \mathrm{C}\right]$ & 0,32 & 0,5 \\
\hline $\begin{array}{l}\text { Thermal expansion ratio } \\
{\left[10-6 /{ }^{\circ} \mathrm{C}\right]}\end{array}$ & 11 & 17,5 \\
\hline $\begin{array}{l}\text { Ultimate tensile } \\
\text { strength[MPa] }\end{array}$ & $754-960$ & 500 \\
\hline Young modulus[GPa] & $40(\mathrm{M}), 75(\mathrm{~A})$ & 193 \\
\hline
\end{tabular}

Tab. 2. Basic properties of steel 304 and nitinol

\section{EXPERIMENTAL}

As welding method plasma arc welding was used. Micro plasma arc welding power source EWM Microplasma 50 was used. Plasma and shielding gas are argon Ar with purity 4.6. Current was set between 4-6 A.

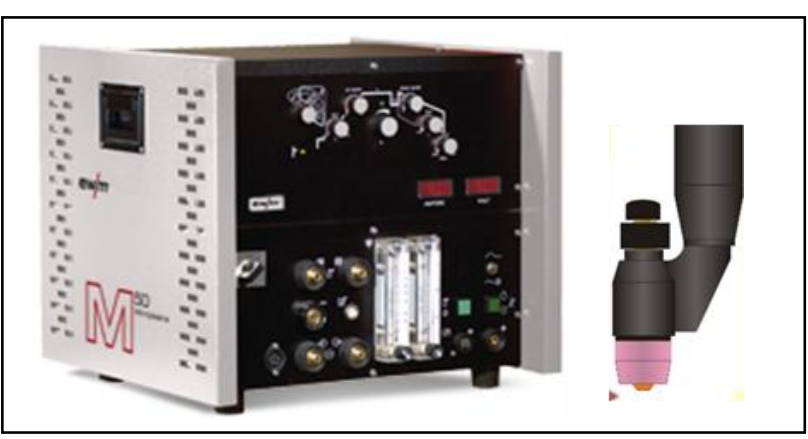

Fig. 2. PAW welding source - Microplasma 50, with welding torch

Observation of metallographic samples by optical microscopy, tensile strength and microhardness measurement were the main experimental means to control quality of the weld.

\section{RESULTS}

\subsection{Tensile strength test of NiTi wire}

To observe the mechanical properties of the NiTi wire, tensile strength test was done - 1 . wire as supplied, 2. wire locally heated, 3 . butt welded $\mathrm{NiTi}+\mathrm{NiTi}$ wire. The purpose of this testing was to estimate what is influence of heat input on properties of NiTi wire. Sample 2 was locally heated upto high temperature (almost fusion temp) with PAW torch in Ar shielding atmosphere. Sample 3 composed from 2 butt welded wires. Parameters of PAW process were same for samples 2, 3.

Results for NiTi wire in as supplied conditions are visible at Fig. 2. We can notice plateau of superelastic behavior at stress of $440 \mathrm{MPa}$ (the value can oscilate between 400-500 MPa), typical for NiTi in austenitic phase. The tensile strength of this sample was $1100 \mathrm{MPa}$. Values of mechanical strength, superelastic behavior are according to expectation for BM [2]. Mode of wire fracture was ductile.

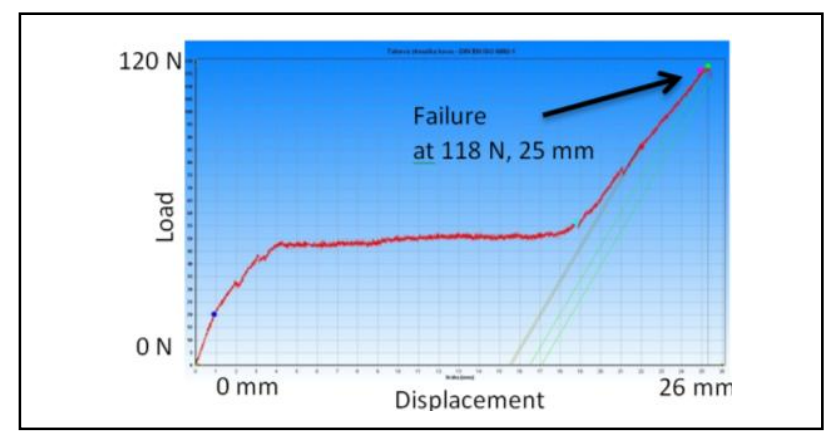

Fig. 3. Tensile strength test of as supplied NiTi wire

Sample 2,3 (locally heated and butt welded wire) did show very similar results, thus only 1 representative graph is show at Fig. 3. Change of properties is obvious.

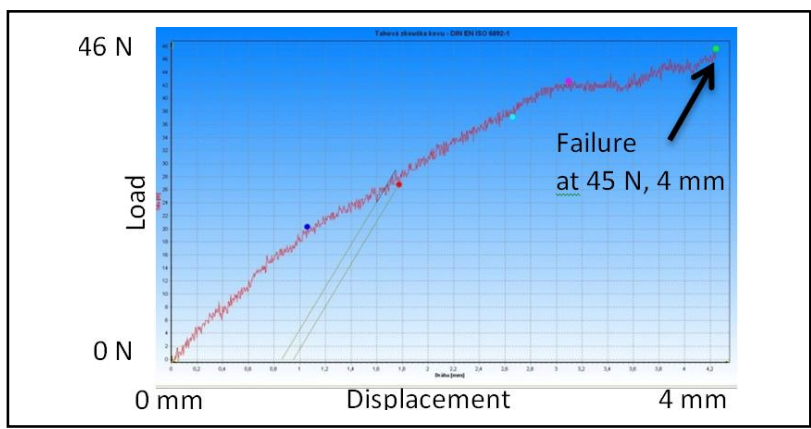

Fig. 4. Tensile strength test of as butt welded NiTi+NiTi wire

The results of of tensile strength test are shown in Tab. 3. We can observe substantial degradation of mechanical properties of NiTi wire by heat input.

\begin{tabular}{|c|c|}
\hline Sample & $\mathrm{R}_{\mathrm{m}}[\mathrm{MPa}]$ \\
\hline 1. NiTi as supplied & 1098 \\
\hline 2. NiTi locally heated & 462 \\
\hline 3. NiTi butt welded & 443 \\
\hline
\end{tabular}

Tab. 3. Results of ulttimate tensile strength of NiTi wire

Decrease of mechanical properties, as tensile strength and elongation was noted by other researchers, especially when heat input, overheating is too high. This is caused by solute segragation, grain coarsening and dendritic 
structure. On the other hand, when heat input is limited, as possible by laser source, the tensile strength, elastic properties can decrease only little compared to BM $[6,8]$.

\subsection{Influence of gas shielding on welds}

Proper gas shielding during welding and heat treatment is very necessary for $\mathrm{NiTi}$, because $\mathrm{NiTi}$ is very reactive with $\mathrm{N}_{2}$ and $\mathrm{O}_{2}$, forming nitrides and oxides, embritelling the material.

At the beginning micro PAW torch orifice as source for shielding gas protection welds were done. Sample welded with PAW torch near the orifice with Argon gas flow of $51 / \mathrm{min}$ is show at Fig. 5. The gas shielding at the torch orifice is not good enough, because oxides form on the surface and are present also at weld metal (WM) microstructure, because hardness of WM was on average $580 \mathrm{HV} 0.5$, considerable increase compared with $350 \mathrm{HV}$ of base material (BM). This hardness increase is probably caused by formation of brittle intermetallic compoung $\mathrm{Ti}_{2} \mathrm{Ni}$ (typically $700 \mathrm{HV}$ [9]). As noted on metallography cut, Fig. 8 left side, structure with very fine columnar dendrites did form (secondary dendritic arms had spacing 1-4 um). Actually from ternary Ti-Ni$\mathrm{O}$ diagram it can be seen that oxygen presence is promoting solidification of $\mathrm{Ti}_{2} \mathrm{Ni}$ phase. Probably the dark dendrites at oxidized sample at Fig. 8 are composed of $\mathrm{Ti}_{2} \mathrm{Ni}[9,10]$, while NiTi is the rest.

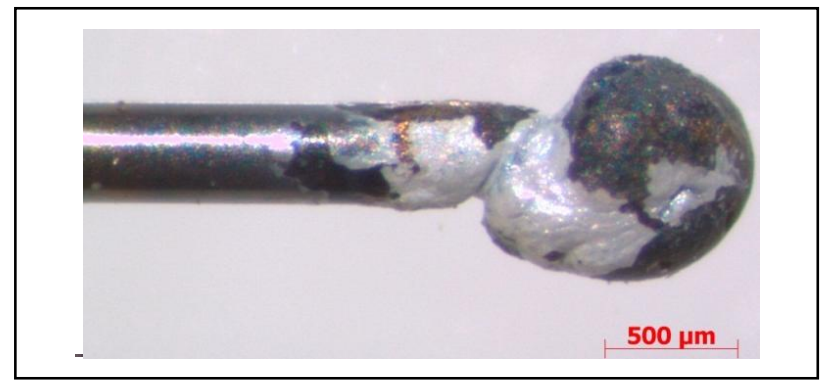

Fig. 5. NiTi wire welded at the welding torch orifice

Special chamber in shape of tube, for NiTi welding was created to ensure $100 \% \mathrm{Ar}$ shielding without presence of any $\mathrm{O}_{2}, \mathrm{~N}_{2}$. Welded NiTi in good $\mathrm{Ar}$ shielding gives perfect sphere without any formed oxides, as at Fig. 6. All remaining welds were done in this protective chamber.

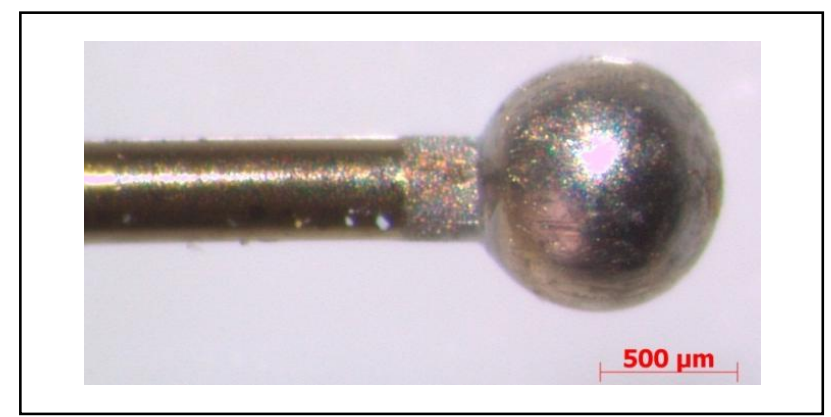

Fig. 6. NiTi wire welded inside the Ar shielding chamber

According to metallography, Fig. 7, Fig. 8 right side, the grain size has substantialy increased in WM. Also in HAZ there is visible substantial grain growth. In the BM the grain size is in the range 10-20 um, in HAZ in range $50 \mathrm{um}$ and WM exhibits large grains of $100 \mathrm{um}$. Average hardness of WM is 265 HV0.5 and the hardness of HAZ changes from $265 \mathrm{HV}$ of WM to $350 \mathrm{HV}$ of $\mathrm{BM}$. Hardness decrease is connected with grain growth during heating [7]. Measurement of HAZ length is $2.5 \mathrm{~mm}$.

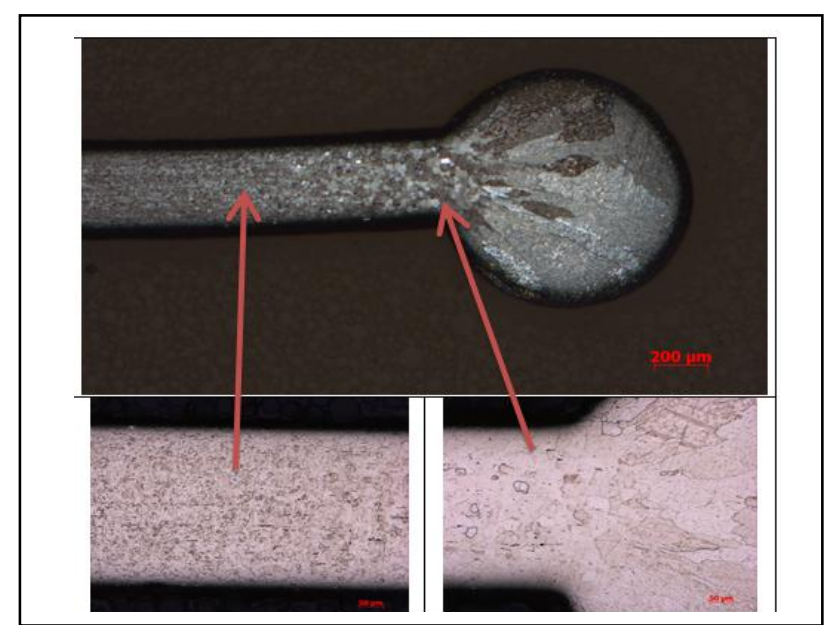

Fig. 7. Metallographic macro and micrographs - mag. 25x, 100x

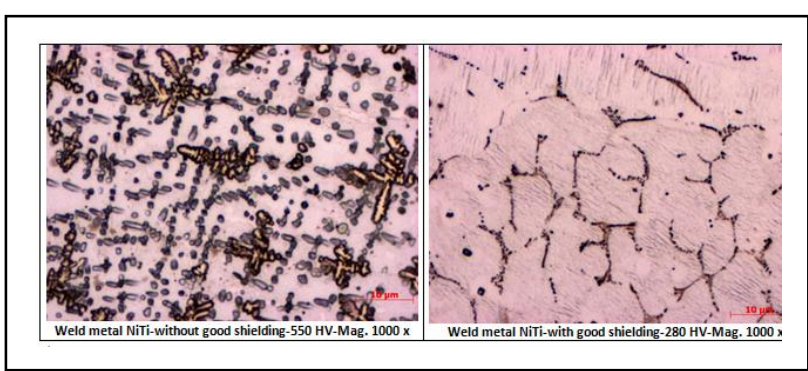

Fig. 8. Microstructure of NiTi wire welded at the welding torch orifice (left figure) and at special chamger (right figure)

At Fig. 8 left side is shown the weld microstructure with fine $\mathrm{Ti}_{2} \mathrm{Ni}$ dendrites, when welded at torch orifice (oxides contamination). At Fig. 8 right side is shown WM microstructure with big grains and precipitates along boundaries of weld done in protective chamber.

\subsection{Heterogenous welds NiTi+304}

Example of heterogenous welds as created between the small tapered end of NiTi wire and steel spring is at Fig. 7. The arc was started between tapered end of wire, diameter $0.2 \mathrm{~mm}$, and then by force of surface tension on liquid molten pool, the melt receded and filled the braid and created the joint. Because the joint itself is created by heat input mainly into the NiTi wire, with fusion temperature below of 304 steel, the created joint has characteristics of brazed joint more than weld. Shown joint is shaped according to specification, with semi spherical end. Weld was produced by hand, current $5 \mathrm{~A}$, Ar shielding 5 1/min.

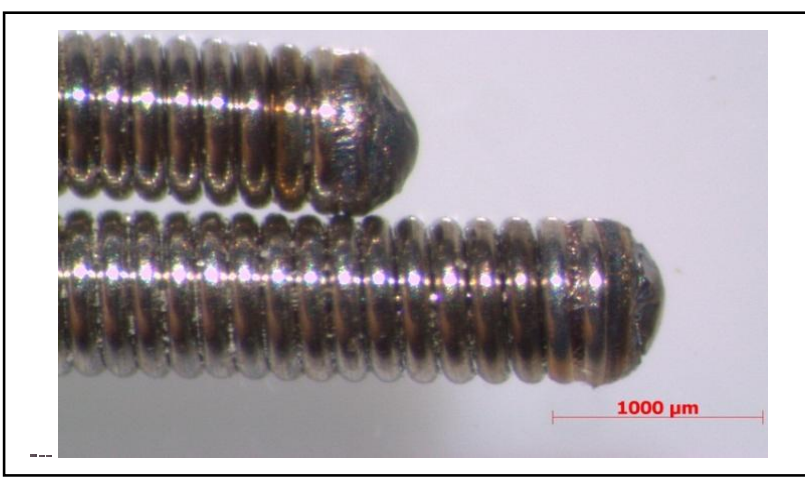

Fig. 9. Heterogenous weld NiTi+304 


\subsection{Tensile testing of joints}

Five samples of dissimilar joints were tensile strength tested. Because the cross section of the joint is same with braid diameter and the tapered end of NiTi has only diam. $0.2 \mathrm{~mm}$, the fracture occurred always in tapered NiTi wire and not the joint itself. The results are shown at Tab. 4. The forces necessary for fracture were very small, at maximum $20 \mathrm{~N}$ and average value of tensile strength of heterogenous welds is $420 \mathrm{MPa}$ (calculated for diam. $0.2 \mathrm{~mm}$ ). The biggest and smallest values were excluded from the average. These values are actually tensile strength of heat affected NiTi wire and are close to values at Tab. 3 .

\begin{tabular}{|c|c|c|}
\hline Weld sample & $\mathrm{F}[\mathrm{N}]$ & Approx. $\mathrm{R}_{\mathrm{m}}[\mathrm{MPa}]$ \\
\hline 1. & 12.6 & 406 \\
\hline 2. & 13.5 & 435 \\
\hline 3. & 13 & 419 \\
\hline 4.excluded & 4.9 & 158 \\
\hline 5. excluded & 20.7 & 668 \\
\hline Average & & $\mathbf{4 2 0}$ \\
\hline
\end{tabular}

Tab. 4. Results of ultimate tensile strength of heterogenous welds

\subsection{Hardness}

Hardness of BM, HAZ for homogenous and heterogenous welds was measured. Base metal (BM) hardness is approx. $350 \mathrm{HV}$.

\begin{tabular}{|l|l|l|}
\hline Weld sample & WM [HV0.5] & HAZ [HV0.5] \\
\hline NiTi BM & 350 & \\
\hline 304 BM & 135 & \\
\hline Oxidized sample - Fig. 5 & 580 & 255 \\
\hline Non-oxidized sample Fig. 6 & $\begin{array}{l}265 \text { (min 220, } \\
\max 340)\end{array}$ & 260 \\
\hline Heterogenous weld- Fig. 9 & $\begin{array}{l}\text { 650 (min 320-max 800) } \\
\text { HAZ out of the macrographs }\end{array}$ \\
\hline
\end{tabular}

Tab. 5. Hardness of welded samples-homogeneous and heterogenous

At some metallographic cuts, the brittle cracks transverse WM grains were found, at Fig. 10. From hardness measurement it was found that hardness in areas with cracks had $635 \mathrm{HV}$ and $700 \mathrm{HV}$. WM formed during welding is very brittle and hard. Most probably because of major heat input is into NiTi wire, probability of creation of intermetallics NiTi-Fe is small. Most probably the brittle phases are caused by low melting $\mathrm{Ti}_{2} \mathrm{Ni}\left(964^{\circ} \mathrm{C}\right)$ phase. $\mathrm{The}^{\mathrm{Ti}} \mathrm{Ti}_{2} \mathrm{Ni}$ presence is enabled by oxygen, which possibly could remain inside the 304 spring braid even thought use of Ar shielding during welding. There can be also precipitation of small size $\mathrm{Ni}_{4} \mathrm{Ti}_{3}, \mathrm{Ti}_{2} \mathrm{Ni}$ from austenitic matrix of NiTi [9].

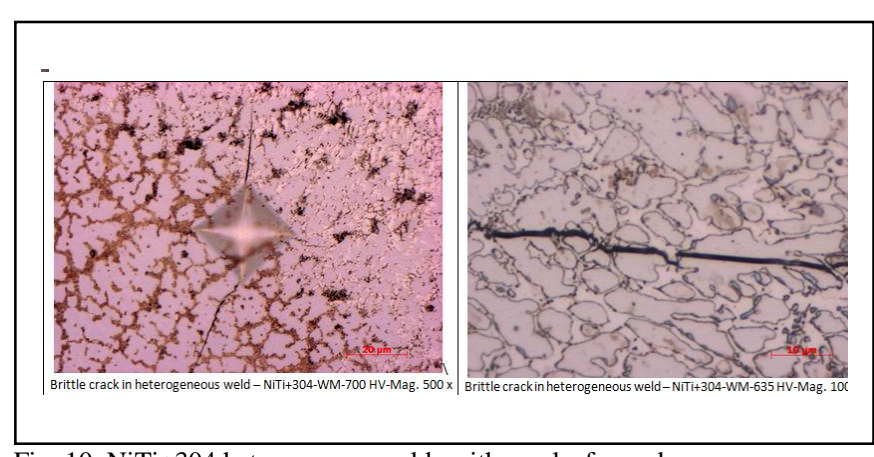

Fig. 10. NiTi+304 heterogenous welds with cracks formed

\section{CONCLUSION}

The preliminary homogenous NiTi and heterogenous welds of NiTi and stainless steel 304 were done in special protective chamber with $\mathrm{Ar}$ shielding gas that succesfully suppressed creation of brittle titanium oxides and nitrides.

Basic NiTi material is of superelastic properties with ultimate tensile strength about $1100 \mathrm{MPa}$. It was found out that heat input by plasma arc welding causes significant changes in the microstructure decreasing significantly the properties, mainly to grain growth, decrease of ultimate tensile strength to $R_{m}=450 \mathrm{MPa}$.

For heterogenous welds brittle phases are created, reaching average hardness of $650 \mathrm{HV}$. When mechanically these samples were tested, they fractured in HAZ with coarse grains of NiTi.

With the purpose of catheter improvement NiTi superelastic wire was supposed to be used in exchange of standardly used 304 wires. By process of PAW welding even at minimum heat input the negative changes in $\mathrm{NiTi}$ occur that decrease its usability for designed purpose. $\mathrm{NiTi}+304$ heterogenous welds of high quality are unable to be produced by PAW. The weldability can be solved by change of materials, product desings, welding method (laser welding) or heat treatment after welding. The future research will most probably employ laser welding in special inert gas protection chamber.

\section{ACKNOWLEDGEMENTS}

Research was supported by grant SGS OHK 2-038/10.

\section{REFERENCES}

[1] Buehler W. J., W8ang F. E. (1968) A summary of recent research on the Nitinol alloys and their potential application in ocean engineering. Ocean Engineering 1, 105-20

[2] Poncet P. P. APPLICATIONS OF SUPERELASTIC NITINOL TUBING, Available from: Memry corporation, http://www. memry.com/sites/default/files/documents/Applications_Superelast ic\%E2\%80\%93NiTI_tube.pdf, Accessed: 2012-08-09

[3] Akselsen O.,(2010) Joining of shape memory alloys, Available from: http://www.intechopen.com/books/shape-memory-alloys /joining-of-shape-memory-alloys, Accessed: 2012-08-09

[4] Eijk C., (2003) Plasma Welding of NiTi to NiTi, Stainless Steel and Hastelloy C276, ASM Materials Solutions Conference, USA

[5] Tuissi A. Bassani P. (2003) $\mathrm{CO}_{2}$ laser welding of NiTi base alloys, Proceeding of SMST 2003, ASM Intertnational

[6] Schuessler A., Piper M. (2004) BOUNDARIES FOR THE USE OF NITINOL IN MEDICAL APPLICATIONS, SMST-2004: Proc. of the Internat. Conf. on Shape Memory and Superelastic Technologies

[7] Haas T., Schuessler A. (1999). Welding and joining of TiNi Shape Memory Alloys, Available from: http://www.admedes.com/sites/files/admedes/files/Welding_and_ Joining_of_TiNi_Shape_Memory_Alloys_Engineering_Aspects_ and_Medical_Applications.pdf, Accessed: 2012-08-09

[8] Khan M., Panda S., Zhou Y. (2008) Effects of welding parameters on laser welded nitinol, Materials Transactions, Vol. 49, No. 11, The Japan Institute of Metals

[9] Chatterjee S., Abinandanan T., Chattopadhyay K. (2008) Phase formation in $\mathrm{Ti} / \mathrm{Ni}$ dissimilar welds, Materials Science and Engineering A, 490 (1-2), pp. 7-15

[10] Duerig T. (2011), Nitinol - alloying and composition, SMST eElastic newsletter, ASM International, Available from:www.asminternational.org 